ARTICLE OPEN

\title{
Chronic obstructive pulmonary disease hospital admissions and drugs - unexpected positive associations: a retrospective general practice cohort study
}

\author{
Timothy H Harries ${ }^{1}$, Paul T Seed ${ }^{1}$, Simon Jones ${ }^{2}$, Peter Schofield ${ }^{1}$ and Patrick White ${ }^{1}$
}

BACKGROUND: Increased prescribing of inhaled long-acting anti-muscarinic (LAMA) and combined inhaled long-acting $\beta_{2}$-agonist and corticosteroid (LABA+ICS) drugs for the treatment of chronic obstructive pulmonary disease (COPD) has led to hopes of reduced hospital admissions from this disease.

AIMS: To investigate the impact of rising primary care prescribing of LAMA and LABA+ICS drugs on COPD admissions.

METHODS: This retrospective cohort study of general practice COPD admission and prescribing data between 2007 and 2010 comprised a representative group of 806 English general practices (population 5,264,506). Outcome measures were practice rates of COPD patient admissions and prescription costs of LAMA and LABA+ICS. General practice characteristics were based on the UK quality and outcomes framework.

RESULTS: Rates of COPD admissions remained stable from 2001 to 2010. Practice-prescribing volumes of LAMA per practice patient and LABA+ICS per practice patient increased by 61 and 26\%, respectively, between 2007 and 2010. Correlation between costs of LAMA and those of LABA+ICS increased year on year, and was the highest in 2010 (Pearson's $r=0.68$; 95\% confidence interval (CI), 0.64-0.72). Practice COPD admission rates were positively predicted by practice-prescribing volumes of LAMA (2010: $B=1.23,95 \%$ $\mathrm{Cl}, 0.61-1.85)$ and of LABA+ICS (2010: $B=0.32,95 \% \mathrm{Cl}, 0.12-0.52)$ when controlling for practice list size, COPD prevalence and deprivation.

CONCLUSION: The increase in the prescribing of LAMA and LABA+ICS inhalers was not associated with the predicted fall in hospital admission rates for COPD patients. The positive correlation between high practice COPD prescribing and high practice COPD admissions was not explained.

npj Primary Care Respiratory Medicine (2014) 24, Article number: 14006; doi:10.1038/npjpcrm.2014.6; published online 20 May 2014

\section{INTRODUCTION}

Chronic obstructive pulmonary disease (COPD) is a leading cause of death and of emergency hospital admissions worldwide. ${ }^{1,2}$ The efficacy of COPD drugs in reducing exacerbations and hospital admissions and improving the quality of life has been reported in clinical trials. ${ }^{3-6}$ The success of the three main classes of COPD drugs - the inhaled long-acting muscarinic antagonist (LAMA) bronchodilator tiotropium, inhaled long-acting $\beta_{2}$-agonists (LABAs), and combined LABA and inhaled corticosteroid $(\mathrm{LABA}+\mathrm{ICS})$ inhalers-has transformed the perception of the drug treatment of the disease.

Drug treatment of COPD is a major cost to the UK National Health Service (NHS). The LABA+ICS combination inhaler of salmeterol-fluticasone was the single most costly drug product prescribed by general practitioners in England in 2011. ${ }^{7}$ Between January 2007 and January 2011 in England the annual spending on LAMAs increased from $£ 78$ million to $£ 130$ million, an increase of $65 \%$, and that on LABA+ICS increased from $£ 385$ million to $£ 498$ million, an increase of $29 \%$ (Appendix), at a time when spending on LABAs fell by $25 \%$.

Monotherapy with LAMA or LABA improves respiratory symptoms and quality of life and leads to fewer COPD exacerbations. ${ }^{8}$ Treatment with LABA+ICS (ICS monotherapy is contraindicated in COPD) reduces the rate of moderate/severe COPD exacerbations and reduces exacerbation-related admissions when compared with placebo. ${ }^{4}$ When compared with LABA, LABA + ICS significantly reduces exacerbations with no difference in admissions. $^{9}$

Despite the benefits of LAMA in reducing the frequency of COPD exacerbations, its effect on exacerbation-related admissions is less clear. ${ }^{10}$ When compared with placebo, the LAMA tiotropium reduces the proportion of patients with one or more exacerbations requiring hospitalisation. ${ }^{11,12}$ Subgroup analysis by severity of the UPLIFT trial found this difference to be not significant in patients with severe/very severe COPD, those most likely to be admitted with exacerbations. ${ }^{12}$

Few studies have examined the translation of these findings into everyday clinical settings. A meta-analysis of LAMA trials and a retrospective analysis of COPD prescribing suggested that the effectiveness of LAMA in reducing COPD admissions in routine practice was at best limited and in other circumstances may have been associated with increased risk. ${ }^{10,13}$ Furthermore, a cost-utility analysis concluded that LAMA had an unfavourable costeffectiveness ratio. $^{14}$

In the NHS, the majority of prescribing of LAMA and LABA+ICS is undertaken by general practitioners in the community. ${ }^{15}$ It was

\footnotetext{
'King's College London, King's Health Partners, Division of Health and Social Care Research, London, UK and ${ }^{2}$ Department of Health Care Management and Policy, University of Surrey, Guildford, Surrey, UK.

Correspondence: TH Harries (timothy.harries@kcl.ac.uk)

Received 19 October 2013; revised 10 January 2014; accepted 8 February 2014
} 
hoped that these drugs would reduce the risk of admission from COPD and consequently reduce the healthcare-related costs of the disease. ${ }^{16,17}$

The aim of this study was to determine whether the increasing rates of use of LAMA and LABA+ICS in the NHS were reflected in a reduction in the rate of admissions for COPD and whether general practices with higher rates of prescribing of these drugs had fewer COPD admissions compared with low-prescribing practices. LABAs were excluded from the analysis because their prescription declined throughout the study.

\section{MATERIALS AND METHODS}

Study design

We conducted a retrospective cohort study of general practice COPD admissions and inhaler use in the English NHS using data from two independent sources: the NHS Information Centre and the NHS Business Services Authority (NHSBSA). Unit of analysis was NHS general practice.

\section{Participating practices}

At the time of this study, general practices in England were grouped in Primary Care Trusts (PCTs), managerial groupings comprising around 50-60 practices. ${ }^{18}$ Selection of study practices was limited by constraints imposed by the NHSBSA, which provided prescription-dispensing data in response to requests made under the Freedom of Information Act $2000 .{ }^{19}$ To obtain a representative sample of practices with respect to COPD prevalence, we stratified each PCT in England by mean COPD prevalence in patients aged $\geqslant 45$ years within their respective practices and by deprivation using the mean Index of Multiple Deprivation (IMD) score. ${ }^{20}$ IMD is a multidimensional score based on decennial national census data and annual local authority population data reflecting deprivation specific to a geographical area based on the practice address. We made a random selection of 50 PCTs representing the distribution of characteristics by which all PCTs were stratified. From this selection the NHSBSA made a pragmatic selection of 15 PCTs based on the availability of dispensing data. These were data on prescriptions dispensed for which community pharmacists were reimbursed by the NHS.

\section{Practice characteristics}

We obtained characteristics of selected practices from the NHS Information Centre Quality and Outcomes Framework (QOF) database for the years 2006-2010 (Appendix). QOF is the basis of a financial incentive system that was applied to general practices in the form of clinical and administrative performance points. ${ }^{18}$ QOF data, to which there is open access, included practice list size, prevalence of diagnosed COPD, IMD scores and overall and COPD treatment-related QOF points awarded. These demographic and performance characteristics were collected to adjust for their effect in the analysis of the relationship between COPD prescribing and admissions.

\section{Inclusion criteria}

Practices were included if complete data had been obtained on prescriptions for inhaled remedies dispensed by pharmacists for at least 3 of the 4 years from 2007 to 2010 and complete COPD admission data for at least 8 of the 10 years from 2001 to 2010 . At no point were more than 23 practices $(2.9 \%)$ missing from the data analysis. No allowance was made in the analysis for missing data.

\section{Admissions data}

We obtained anonymised patient-level data on COPD patient admissions from the NHS Information Centre Hospital Episodes Statistics database (Appendix). A primary diagnosis field captured all patient admissions in England from 2001 to 2010 with a primary diagnosis of COPD (ICD-10 codes J40-J44) for patients within practices in the selected PCTs. We undertook analysis by patient admitted per year rather than by each admission per year to avoid the potential distortion that would be associated with multiple admissions of the same patient.

\section{Prescribing data}

We sought prescribing data from the NHSBSA for all practices within the 15 PCTs. Data were obtainable from 2007 to 2010 and not available prior to 2007. We based our assessment on prescription costs as these were the best estimate of the volume of prescriptions dispensed. Costs of drugs were stable and uniform within the NHS and more accurately reflected the volume of drug dispensed than the item issued, which did not include the volume or amount of drug. We chose not to use Specific Therapeutic group Age-sex weightings Related Prescribing Units as our unit of prescribing as prescribing for COPD is predominantly in patients over 45 years of age. Instead, we controlled for list size, COPD prevalence and practice deprivation in the analysis.

Total costs of NHS prescriptions dispensed presented as Net Ingredient Cost were calculated by the NHSBSA for each practice. Net Ingredient Cost was the cost to the NHS of each LAMA and of each LABA+ICS drug dispensed by pharmacists from prescriptions from the study practices (Appendix). Costs and dates of dispensing of each item were aggregated by general practice and by PCT. Aggregated prescribing data could only be obtained from the NHSBSA through freedom of information enquiries. Access to data was restricted. Size limits were imposed on each enquiry, necessitating our making 10 separate requests to the NHSBSA between January 2011 and August 2012. Data on most small practices were withheld by the NHSBSA to prevent the identification of individual prescribers, an action that would contravene the Data Protection Act. ${ }^{21}$ The data we obtained were made available online on the NHSBSA website (Appendix). Prescribing data obtained were independent of underlying disease and may have represented use among asthmatic as well as COPD patients.

\section{Statistical methods}

We based prescribing analysis on the annual prescription (dispensing) costs of LAMA and LABA+ICS per registered practice patient (2007-2010).

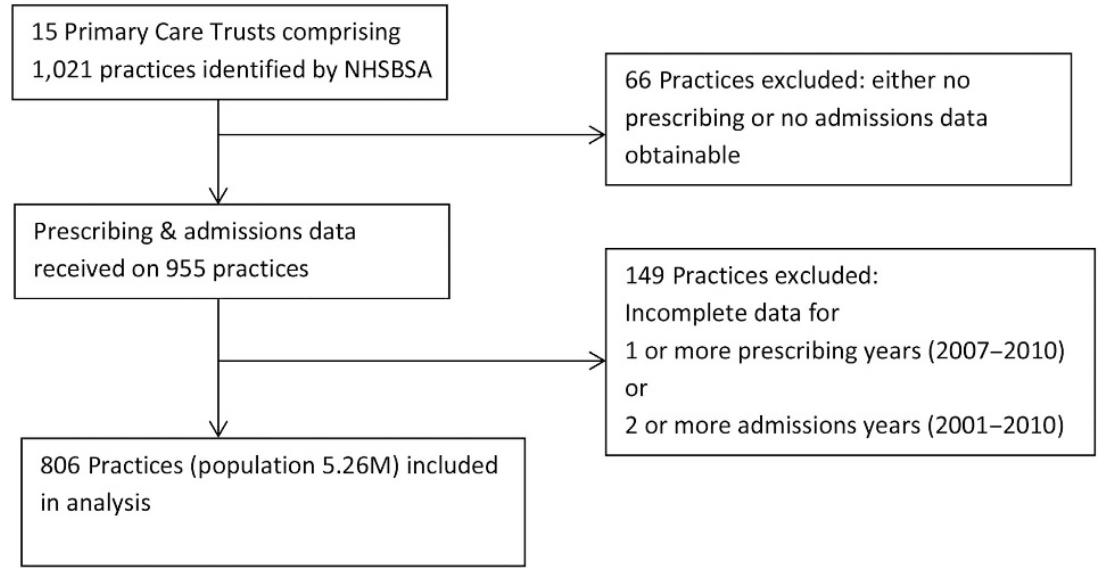

Figure 1. Identification of practices for inclusion in the study. 
We based hospital admission analysis on the annual rate of patients admitted with a COPD exacerbation (2001-2010) per 10,000 registered practice patients.

We sought correlations between general practices' prescription costs per practice patient for LAMA and their prescription costs per practice patient for LABA+ICS from 2007 to 2010. To correct for possible spurious correlation, we calculated the coefficients of the logged costs of LAMA and of LABA+ICS, controlling for the log of practice list size. ${ }^{22,23}$

We used multiple linear regression to examine the relationship in each year between the prescription costs of each drug per practice patient and the rate of COPD patients admitted per 10,000 practice patients. We controlled for the prevalence of diagnosed COPD, IMD score and the practice performance indicators obtained from QOF. We expressed both predictors and outcomes as rates per practice patient, and included a correction using the inverse of the list size (1/list size) according to the method of Kronmal to correct for possible spurious correlation. ${ }^{23}$

As confirmatory analysis we fitted a multiple linear regression model, correcting for practice list size and COPD prevalence, according to the formula:

$\log ($ COPD patient admitted $)=\log ($ LAMA cost $)+\log ($ LABA + ICS cost $)$ $+\log$ (practice list size) + log (IMD score) + log (total QOF score) + log (COPD QOF score) + log (COPD registered patients).

We used the statistical package SPSS version 20 for data analysis. Ethical approval was not required for this study as data were at practice level.

\section{RESULTS}

Participants

We included data from 806 practices (population 5,264,506) (Figure 1). We excluded 215 practices because of insufficient data. Study practices differed from national practices in their greater deprivation and prevalence of diagnosed COPD, but were no different in practice size or drug costs (Table 1).

QOF data were available for 162 of the 215 excluded practices. These were significantly smaller (list size mean difference 3,599; 95\% confidence interval $(\mathrm{Cl}), 2,991.7-4,206.2)$, included more single-handed practices (58.1 vs. $8.7 \%$ ) (difference $49.4 \%, 95 \% \mathrm{Cl}$, 41.4-57.4) and were more deprived (IMD score mean difference 7.0; $95 \% \mathrm{Cl}, 4.0-10.1)$ than the study practices.

Prevalence of diagnosed COPD in study practices increased by $0.13 \%(95 \% \mathrm{Cl}, 0.11-0.16)$ from 1.79 to $1.92 \%$ from 2007 to 2010 (Figure 2). Figure 2 includes reference to the predicted national prevalence of COPD (2.58\%) in $2010 .^{24}$ Prevalence of diagnosed asthma in study practices increased by $0.21 \%(95 \% \mathrm{Cl}, 0.17-0.26)$ from 5.93 to $6.14 \%$ over this period.

Prescribing data

The annual prescribing cost per practice patient (all patients) of LAMA increased by $61 \%$ from a mean of $£ 1.81$ in 2007 to $£ 2.90$ in 2010 (mean difference $£ 1.09,95 \% \mathrm{Cl}, 1.03-1.16$ ). LABA+ICS cost increased by $26 \%$ from a mean of $£ 7.87$ in 2007 to $£ 9.89$ in 2010 (mean difference $£ 2.02,95 \% \mathrm{Cl}, 1.89-2.15$; Figure 3 ). The median (interquartile range) cost per practice patient in the same period increased from $£ 1.59(1.01-2.37)$ to $£ 2.66(1.82-3.69)$ for LAMA and from $£ 7.44(5.35-10.11)$ to $£ 9.79(7.10-12.34)$ for LABA+ICS.

\section{Admissions data}

The annual rate of COPD patients admitted per 10,000 practice patients increased from a mean (s.d.) of 15.7 (10.2) in 2001 to 18.3 (10.2) in 2010 (mean difference 2.6 patients per 10,000 practice patients, $95 \% \mathrm{Cl}, 1.8-3.3$ ). The median (interquartile range) of COPD patients admitted per 10,000 practice patients varied between a minimum of 13.7 (8.6-20.4) in 2001 and a maximum of 16.1 (9.9-23.5) in 2003 with an annual average median (interquartile range) of 15.5 (10.0-22.4) over 10 years.

To demonstrate the difference between COPD patients admitted and COPD admissions, means of both, including Cls, from 2001 to
Table 1. Study practices (806) compared with all other practices in England (7,439): characteristics drawn from QOF data set 2010

\begin{tabular}{|c|c|c|}
\hline $\begin{array}{l}\text { Practice } \\
\text { characteristic }\end{array}$ & Mean (s.d.) & $\begin{array}{l}\text { Difference between } \\
\text { means }( \pm 95 \% \mathrm{Cl})\end{array}$ \\
\hline \multicolumn{3}{|c|}{ Practice list size } \\
\hline Study & $6,517(3,780)$ & $-166(-133.1$ to 444.7$)$ \\
\hline England & $6,683(4,228)$ & \\
\hline \multicolumn{3}{|l|}{ Males (\%) } \\
\hline Study & $50.7(2.6)$ & $0.4(0.2-0.6)$ \\
\hline England & $50.3(2.9)$ & \\
\hline \multicolumn{3}{|c|}{ Patients aged 45+ (\%) } \\
\hline Study & $39.3(9.5)$ & $-1.2(-2.0$ to -0.6$)$ \\
\hline England & $40.5(10.1)$ & \\
\hline \multicolumn{3}{|c|}{ Patients aged 45-64 (\%) } \\
\hline Study & $24.5(4.9)$ & $-0.6(-1.0$ to -0.3$)$ \\
\hline England & $25.1(4.9)$ & \\
\hline \multicolumn{3}{|c|}{ Patients aged 65-74 (\%) } \\
\hline Study & $7.8(2.6)$ & $-0.3(-0.5$ to -0.1$)$ \\
\hline England & $8.1(3.0)$ & \\
\hline \multicolumn{3}{|c|}{ Patients aged 75+ (\%) } \\
\hline Study & $7.0(2.7)$ & $-0.3(-0.5$ to -0.1$)$ \\
\hline England & $7.3(3.8)$ & \\
\hline \multicolumn{3}{|c|}{ Deprivation score } \\
\hline Study & $33.8(17.6)$ & $8.0(6.6-9.2)$ \\
\hline England & $25.8(17.2)$ & \\
\hline \multicolumn{3}{|c|}{$P C T$ cost of $L A B A+I C S /$ patient $(£)$} \\
\hline Study & $9.60(2.00)$ & $0.57(-0.77$ to 1.90$)$ \\
\hline England & $9.03(2.54)$ & \\
\hline \multicolumn{3}{|c|}{ PCT cost of LAMA/patient ( $€$ ) } \\
\hline Study & $2.64(0.67)$ & $0.26(-0.19$ to 0.71$)$ \\
\hline England & $2.38(0.85)$ & \\
\hline \multicolumn{3}{|c|}{ Diagnosed COPD prevalence (\%) } \\
\hline Study & $1.93(0.88)$ & $0.26(0.19-0.32)$ \\
\hline England & $1.67(0.97)$ & \\
\hline \multicolumn{3}{|c|}{ QOF points/available } \\
\hline Study & $0.948(0.04)$ & $0.001(-0.005$ to 0.003$)$ \\
\hline England & $0.947(0.05)$ & \\
\hline \multicolumn{3}{|c|}{ COPD points/available } \\
\hline Study & $0.981(0.06)$ & $0.008(0.003-0.012)$ \\
\hline England & $0.973(0.10)$ & \\
\hline \multicolumn{3}{|c|}{ Smoking points/available } \\
\hline Study & $0.994(0.04)$ & $0.002(-0.0036$ to 0.0004$)$ \\
\hline England & $0.992(0.03)$ & \\
\hline
\end{tabular}

Abbreviations: $\mathrm{Cl}$, confidence interval; $\mathrm{COPD}$, chronic obstructive pulmonary disease; $L A B A+I C S$, combined inhaled long-acting $\beta_{2}$-agonist and corticosteroid; LAMA, long-acting anti-muscarinic; PCT, Primary Care Trust; QOF, Quality and Outcomes Framework.

2010 are shown in Figure 4. Reference to the year of publication (February 2003) of the first study on the efficacy of the combination of salmeterol-fluticasone in improving exacerbations in COPD is included. $^{3}$ This date was close to that of the introduction of tiotropium in the United Kingdom (September 2002).

\section{Prescribing correlations}

The correlations between the prescribing costs of LAMA per practice patient and those of LABA+ICS per practice patient are 


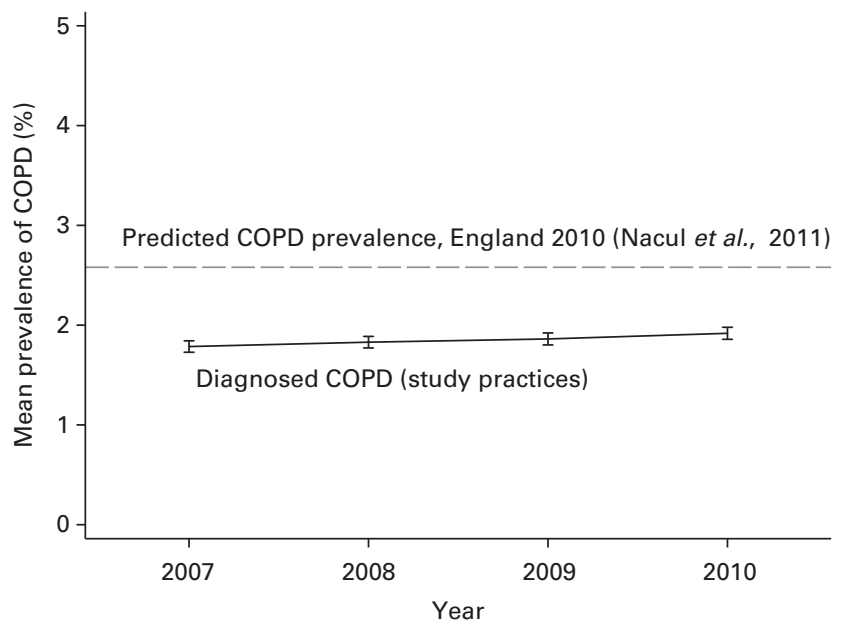

Figure 2. Prevalence ( $\% \pm 95 \%$ confidence interval) of diagnosed chronic obstructive pulmonary disease (COPD) in study practices 2007-2010 (dashed line shows predicted prevalence of COPD in 2010). ${ }^{24}$

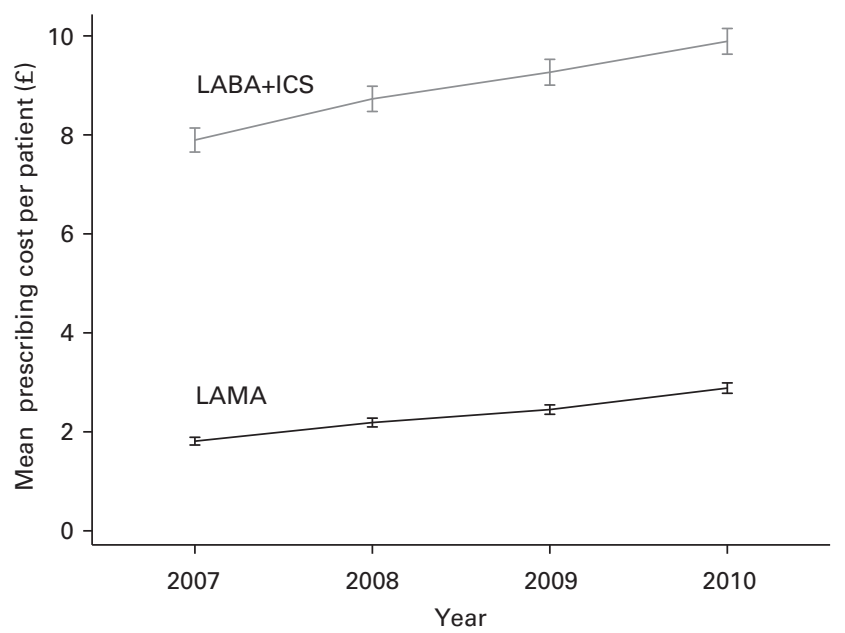

Figure 3. Annual rates (mean $\pm 95 \%$ confidence interval) of LAMA and LABA+ICS prescribing costs per practice patient (all patients). Costs expressed based on all patients on the practice list to standardise prescribing rates. The unit cost to the NHS of LAMA fell by $7.3 \%$ and the unit cost to the NHS of LABA+ICS fell by up to $4.5 \%$ between 2007 and 2010 (BNF.org). LAMA, long-acting anti-muscarinic; LABA+ICS, combined inhaled long-acting $\beta_{2}$-agonist and corticosteroid; NHS, National Health Service.

shown in Table 2. To test for spurious correlation, partial correlations of the log of the cost of LAMA and log of the cost of $L A B A+I C S$, controlling for the log of practice list size, are included.

\section{Regression and sensitivity analyses}

Estimates for the association between prescribing costs and COPD patient admission rates (2007-2010) are shown in Table 3. Results were adjusted for COPD prevalence, IMD score, QOF points (total and COPD specific) and inverse of practice size (1/practice size), which were significantly associated with COPD admissions in univariate analysis.

Numbers in the table can be interpreted as additional admissions/10,000 patients/£ spent on the drug per practice patient.
Table 2. Correlation between rates of practice prescribing cost per practice patient of LAMA and LABA+ICS (with partial correlation of log of the cost of LAMA and the log of the cost of LABA+ICS when controlling for the log of the practice list size)

\begin{tabular}{lcc}
\hline Year & $\begin{array}{c}\text { Rate LAMA versus } \\
\text { Rate LABA+ICS }\end{array}$ & $\begin{array}{c}\text { Log LAMA cost versus } \\
\text { Log LABA+ICS cost }\end{array}$ \\
\hline & $R_{1}( \pm 95 \% \mathrm{Cl})$ & $R_{2}( \pm 95 \% \mathrm{Cl})$ \\
$2007(n=798)$ & $0.52(0.47-0.57)$ & $0.56(0.52-0.61)$ \\
$2008(n=801)$ & $0.60(0.55-0.64)$ & $0.63(0.59-0.67)$ \\
$2009(n=804)$ & $0.63(0.59-0.67)$ & $0.67(0.63-0.71)$ \\
$2010(n=796)$ & $0.68(0.64-0.72)$ & $0.73(0.69-0.76)$ \\
\hline$R_{1}$ is Pearson's correlation (unadjusted for practice list size). $R_{2}$ is Partial \\
correlation (adjusted for log practice list size). $n$ is number of practices. \\
Abbreviations: Cl, confidence interval; LABA+ICS, combined inhaled long- \\
acting $\beta_{2}$-agonist and corticosteroid; LAMA, long-acting anti-muscarinic. \\
\hline
\end{tabular}

Confirmatory analysis to exclude spurious correlation was carried out using a log transformation model of prescribing to predict the log (base 10) of the hospital admission rate (Table 4). A significant increase in admissions was observed with greater prescribing of LAMA between 2008 and 2010 and with greater prescribing of LABA+ICS in 2007 and 2009.

\section{DISCUSSION}

Main findings

Practices that were high prescribers of LAMA and LABA+ICS drugs had higher rates of COPD admission compared with lowprescribing practices. This relationship was observed during a time of significant increase in national prescribing of both drug classes and unchanging rates of COPD admissions. Practice rates of prescribing of LAMA and LABA+ICS were strongly correlated. There was no evidence of reciprocal prescribing between these two groups of drugs whose effects on COPD in clinical trials were similar. ${ }^{25}$ There was considerable variation in prescribing across practices. The rates of prescribing of LAMA and LABA+ICS in those practices within the lowest quartile were respectively less than half and almost half of those practices within the highest quartile. The small changes in the diagnosed prevalence of COPD and asthma were unlikely to be responsible for the increased prescribing of these drugs. There was no evidence of a change in true prevalence of COPD and hence it is probable that the small increase in diagnosed prevalence of COPD resulted from improved recognition of the disease or changes in clinical recording practice.

\section{Strengths and limitations of this study}

The pattern of increasing inhaled medication prescription volume and unchanging rate of COPD patient admissions and the consistency of the relationship between practice-level prescribing and COPD admissions throughout the study were striking. Prescribing data were based on NHS prescriptions dispensed, a better reflection of the true impact of the drugs compared with prescribers' records, which would reflect prescriber intentions rather than patient use. Study practices did not differ from the practices in England other than their being situated in more deprived areas, the most likely explanation for their high COPD prevalence. The increase in the prescribing of COPD drugs in study practices from 2007 to 2010 matched that in England. It is likely that the study findings reflected the pattern of care in England.

Concerns regarding the accuracy of routinely collected data sources, including Hospital Episodes Statistics admissions data, have been ameliorated by improvements in quality over recent 


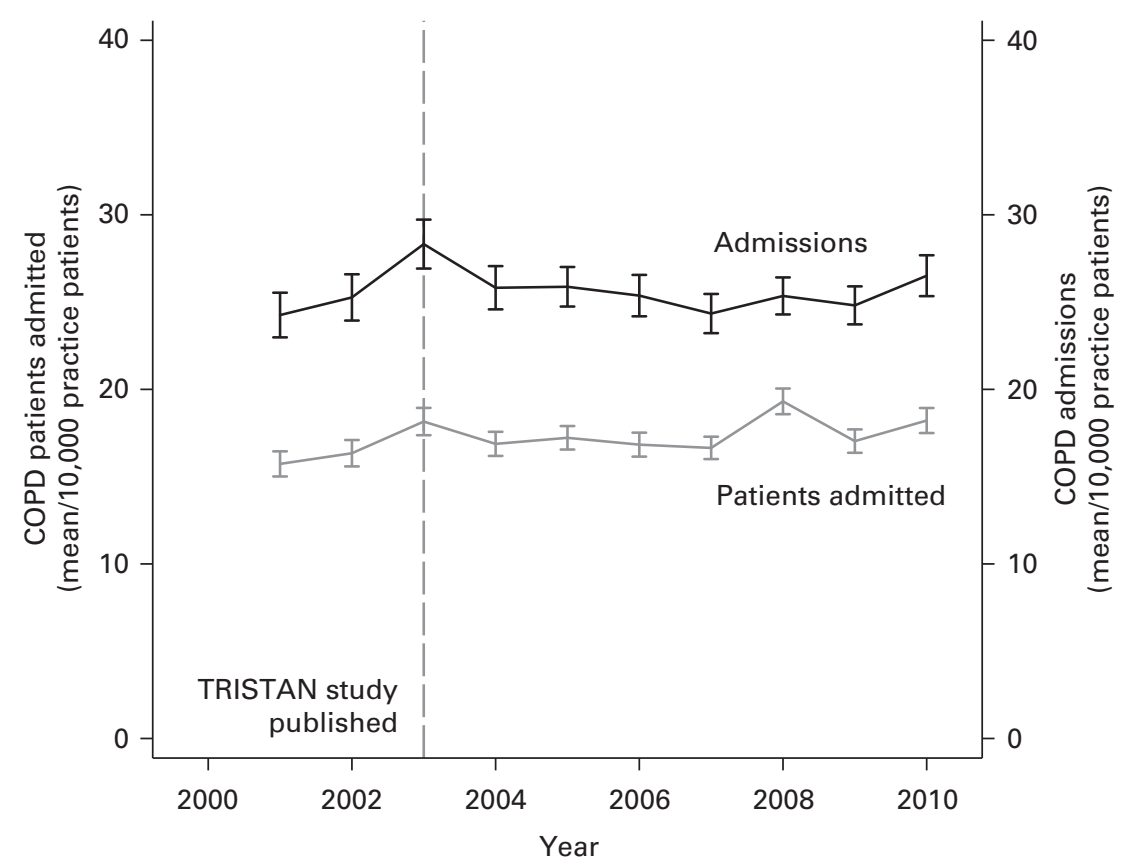

Figure 4. Annual rates (mean $\pm 95 \%$ confidence interval) of chronic obstructive pulmonary disease (COPD) patients admitted and of all COPD admissions per 10,000 practice patients.

Table 3. Association of practice rates of prescribing of LAMA and LABA+ICS with practice rates of patients admitted for COPD

\begin{tabular}{|c|c|c|c|c|}
\hline Predictor variable & $2007(\mathrm{n}=787)$ & $2008(n=790)$ & $2009(n=797)$ & $2010(n=783)$ \\
\hline LAMA cost/practice patient, $\beta$-statistic $( \pm 95 \% \mathrm{Cl})$ & $0.37(-0.22$ to 0.97$)$ & $1.24(0.58-1.91)$ & $1.12(0.55-1.70)$ & $1.23(0.61-1.85)$ \\
\hline LABA+ICS cost/practice patient, $\beta$-statistic $( \pm 95 \% \mathrm{Cl})$ & $0.39(0.22-0.56)$ & $0.28(0.08-0.48)$ & $0.23(0.05-0.41)$ & $0.32(0.12-0.52)$ \\
\hline
\end{tabular}

\begin{tabular}{|c|c|c|c|c|}
\hline \multirow[b]{2}{*}{ Predictor variable } & \multicolumn{4}{|c|}{ Regression outcome $2007-2010$ ( $\pm 95 \%$ Cl) } \\
\hline & 2007 & 2008 & 2009 & 2010 \\
\hline Log10 LAMA cost, $\beta$-statistic ( $\pm 95 \% \mathrm{Cl})$ & $0.02(-0.05$ to 0.09$)$ & $0.22(0.13-0.30)$ & $0.19(0.10-0.28)$ & $0.29(0.19-0.40)$ \\
\hline Log10 LABA+ICS cost, $\beta$-statistic $( \pm 95 \% \mathrm{Cl})$ & $0.20(0.13-0.28)$ & $0.07(-0.03$ to 0.16$)$ & $0.11(0.01-0.21)$ & $0.10(-0.01$ to 0.22$)$ \\
\hline
\end{tabular}

years. ${ }^{26}$ The relative stability of annual admission rates in our data and the consistency of the relationship between admissions and prescribing gave cause for confidence.

Analysing data at a practice level rather than at patient level has the disadvantage in a study with an ecological element such as this of missing possible explanatory variables that are exclusive to individual patients. Disease severity is an important example. Another possible confounder is the actual level of use of medication by individuals. The advantage of being able to analyse a large cohort of practices as we have done here is that the large number of COPD admissions observed has given us the power to examine the relationship between prescribing and admissions, 
which would be impossible at individual practice level. As admissions occur mainly among the most severely affected COPD patients it may be surmised that the patients admitted were predominantly those with severe disease., ${ }^{4,27}$ We cannot assume that it was for these patients that LAMA and LABA+ICS were prescribed. However, the positive association between prescribing and admissions was strong throughout the study when controlling for prevalence, deprivation, prescribing of the other drug type and practice performance data. It would seem perverse to suggest that the significant increase in prescribing took place only in those patients who were not at risk of admission.

The association between high practice rates of prescribing of LAMA and LABA+ICS and high practice rates of COPD admission may be explained by larger numbers of severely affected COPD patients being found in high prescribing practices. If this was the case it would suggest that the drugs were ineffective at reducing admissions, as rates of COPD admission have not fallen following the introduction and progressive increase in rates of prescribing of these drugs. An increased rate of prescription of LABA+ICS to patients with asthma may have contributed to the increasing rate of prescribing of these drugs within the practices.

Interpretation of findings in relation to previously published work The reduction in the frequency of COPD exacerbations seen in clinical trials of LAMA and LABA+ICS has raised the hope that prescribing of these drugs in patients with severe and very severe COPD would reduce COPD admissions, leading to substantial cost savings. ${ }^{4,28,29}$ The lack of evidence for their effect in reducing COPD admissions resonates with concerns of Suissa ${ }^{30}$ about underestimates of the number needed to treat in clinical trials of $L A B A+I C S$, which assessed outcome in terms of frequency of acute exacerbations of COPD assessed.

The positive association between prescribing costs and admissions is unlikely to represent a causal relationship as there is no evidence from clinical trials of such adverse effects. A second possible explanation might be that patients started using these drugs at the time of admission, leading to a cumulative effect of admission-associated prescribing. This does not account for the fact that the rise in drug prescribing far exceeded the small change in the rate of COPD admissions. We consider it more plausible that the association we have observed described the position of these drugs as markers of COPD severity. High practice rates of prescribing of LAMA and LABA+ICS may have indicated those practices with high prevalence of COPD patients with severe and very severe disease, those most at risk of admission. The rising volume of prescribing of these drugs at the practice level appears to have been an increasingly accurate indicator of admission risk within practices.

Implications for future research, policy and practice

As this study examined practice-level associations between prescribing and admissions, future work should assess the relationship between medication use and hospital admissions among individual COPD patients within practices. The importance of these findings may warrant a phase IV clinical trial to assess whether the marginal benefits seen within phase III trials persist within everyday clinical practice.

\section{Conclusions}

The proven effectiveness of LAMA and LABA+ICS in reducing exacerbations has been followed by some scepticism about their role in reducing admissions. ${ }^{4,6,10,13}$ That scepticism is supported by the results of our study. Higher practice prescribing of these drugs was associated with higher rates of COPD admission. Data from the NHSBSA show that spending on these two groups of drugs in 2011 totalled nearly $£ 650$ million per year in England. This is a huge financial burden to the UK taxpayer from the widespread use of prescription drugs, the extent of effectiveness of which in COPD is uncertain.

\section{ACKNOWLEDGEMENTS}

The authors thank Hannah Thornton and Helen Booth for their help with the initial data analysis and Mark Ashworth and Martin Gulliford for their assistance in reviewing the draft paper.

\section{CONTRIBUTIONS}

PW and THH devised the study and all authors contributed to its design. PW, THH and SJ contributed to data collection. PW, THH, PTS and PS contributed to data analysis. PW and $\mathrm{THH}$ wrote the first draft. All authors commented and contributed to the final paper.

\section{COMPETING INTERESTS}

PW has received project grants, consultancy fees, speaker fees and support for attending conferences from a number of pharmaceutical company manufacturers of respiratory drugs, but has no other financial relationships with any organisations that might have an interest in the submitted work. The remaining authors declare no conflict of interest.

\section{FUNDING}

This study is the independent work of the authors. THH was supported by a National Institute for Health Research In-Practice fellowship. No other funding was provided.

\section{REFERENCES}

1 The Burden of Lung Disease. 2nd Edn. A Statistics report from the BTS. http:// www.brit-thoracic.org.uk/Portals/0/Library/BTS\%20Publications/burdeon_of_ lung disease2007.pdf, 2006.

2 NICE. CG101 Chronic obstructive pulmonary disease (update): NICE guideline. at http://publications.nice.org.uk/chronic-obstructive-pulmonary-disease-cg101.

3 Calverley P, Pauwels R, Vestbo J, Jones P, Pride N, Gulsvik A et al. Combined salmeterol and fluticasone in the treatment of chronic obstructive pulmonary disease: a randomised controlled trial. Lancet 2003; 361: 449-456.

4 Calverley PMA, Anderson JA, Celli B, Ferguson GT, Jenkins C, Jones PW et al. Salmeterol and fluticasone propionate and survival in chronic obstructive pulmonary disease. N Engl J Med 2007; 356: 775-789.

5 Wedzicha JA, Calverley PMA, Seemungal TA, Hagan G, Ansari Z, Stockley R. The prevention of chronic obstructive pulmonary disease exacerbations by salmeterol/fluticasone propionate or tiotropium bromide. Am J Respir Crit Care Med 2008; 177: 19-26.

6 Tashkin DP, Celli B, Senn S, Burkhart D, Kesten S, Menjoge S et al. A 4-year trial of tiotropium in chronic obstructive pulmonary disease. N Engl J Med 2008; 359: 1543-1554.

7 Prescription Cost Analysis England 2012. http://www.hscic.gov.uk/searchcatalo gue? productid $=11412 \& q=$ title $\% 3 a \% 22$ Prescription+Cost+Analysis $\% 2 c+$ England\%22+!quarterly\&amp;sort = Relevance\&size = 10\&page = 1\#top, 2013.

8 Spencer S, Karner C, Cates CJ, Evans DJ. Inhaled corticosteroids versus long-acting beta(2)-agonists for chronic obstructive pulmonary disease. Cochrane Database Syst Rev 2011; 12: CD007033.

9 Nannini LJ, Lasserson TJ, Poole P. Combined corticosteroid and long-acting beta(2)-agonist in one inhaler versus long-acting beta(2)-agonists for chronic obstructive pulmonary disease. Cochrane Database Syst Rev 2012; 9: CD006829.

10 Van den Bruel A, Gailly J, Neyt M. Does tiotropium lower exacerbation and hospitalization frequency in COPD patients: results of a meta-analysis. BMC Pulm Med 2010; 10: 50.

11 Yohannes AM, Willgoss TG, Vestbo J. Tiotropium for treatment of stable COPD: a meta-analysis of clinically relevant outcomes. Respir Care 2011; 56 477-487.

12 Karner C, Chong J, Poole P. Tiotropium versus placebo for chronic obstructive pulmonary disease. Cochrane Database Syst Rev 2012; 7: CD009285.

13 Lee TA, Wilke C, Joo M, Stroupe KT, Krishnan JA, Schumock GT et al. Outcomes associated with tiotropium use in patients with chronic obstructive pulmonary disease. Arch Intern Med 2009; 169: 1403-1410. 
14 Neyt M, Devriese S, Thiry N, Van den Bruel A. Tiotropium's cost-effectiveness for the treatment of COPD: a cost-utility analysis under real-world conditions. BMC Pulm Med 2010; 10: 47.

15 NHS Information Centre. Hospital Prescribing, England: 2011. https://catalogue.ic nhs.uk/publications/prescribing/primary/hosp-pres-eng-2011/hosp-pres-eng2011-rep.pdf, 2012.

16 Sin DD, Man SFP. Steroids in COPD: still up in the air? Eur Respir J 2010; 35: 949-951.

17 Bourbeau J. Preventing hospitalization for COPD exacerbations. Semin Respir Crit Care Med 2010; 31: 313-320.

18 Roland M. Linking physicians' pay to the quality of care-a major experiment in the United Kingdom. N Engl J Med 2004; 351: 1448-1454.

19 Independent Review of the impact of the Freedom of Information Act. A report prepared for the department for constitutional affairs. http://webarchive.nationalarchives.gov.uk/\%2B/http:/www.dca.gov.uk/foi/reference/foi-independentreview.pdf, 2006.

20 Payne RA, Abel GA. UK indices of multiple deprivation-a way to make comparisons across constituent countries easier. Health Stat Q 2012; 53: 22-37.

21 Data Protection Act 1998. http://www.legislation.gov.uk/ukpga/1998/29/contents.

$22 \mathrm{Kim} \mathrm{HJ}$. Spurious correlation between ratios with a common divisor. Stat Prob Lett 1999; 44: 383-386.

23 Kronmal RA. Spurious correlation and the fallacy of the ratio standard revisited. $J$ R Stat Soc 1993; 156: 379-392.

24 Nacul L, Soljak M, Samarasundera E, Hopkinson NS, Lacerda E, Indulkar T et al. COPD in England: a comparison of expected, model-based prevalence and observed prevalence from general practice data. J Public Health (Oxf) 2011; 33: 108-116.

25 Welsh EJ, Cates CJ, Poole P. Combination inhaled steroid and long-acting beta2-agonist versus tiotropium for chronic obstructive pulmonary disease. Cochrane Database Syst Rev 2010; 5: CD007891.

26 Improving data quality in the NHS: 2010 - Audit Commission. http://www.auditcommission.gov.uk/2010/08/improving-data-quality-in-the-nhs-2010/.
27 Beeh K-M, Hederer B, Glaab T, Müller A, Rutten-van Moelken M, Kesten S et al. Study design considerations in a large COPD trial comparing effects of tiotropium with salmeterol on exacerbations. Int J Chron Obstruct Pulmon Dis 2009; 4: 119-125.

28 Barr RG, Bourbeau J, Camargo CA, Ram FSF. Tiotropium for stable chronic obstructive pulmonary disease: a meta-analysis. Thorax 2006; 61: 854-862.

29 Mauskopf JA, Baker CL, Monz BU, Juniper MD. Cost effectiveness of tiotropium for chronic obstructive pulmonary disease: a systematic review of the evidence. J Med Econ 2010; 13: 403-417.

30 Suissa S. Number needed to treat in COPD: exacerbations versus pneumonias. Thorax 2013; 68: 540-543.

(a) $(\$$ This work is licensed under a Creative Commons Attributioncc. NonCommercial-NoDerivatives 4.0 International License. The images or other third party material in this article are included in the article's Creative Commons license, unless indicated otherwise in the credit line; if the material is not included under the Creative Commons license, users will need to obtain permission from the license holder to reproduce the material. To view a copy of this license, visit http:// creativecommons.org/licenses/by-nc-nd/4.0/

\section{APPENDIX}

The drug prescribing data from the NHSBSA used during the study are available online.

https://www.ppa.org.uk/foiRequest/foiRequestList.do (Request reference number 512422)

https://www.ppa.org.uk/NHSBSA_foiRequest/foiRequestList.do

(Request reference numbers: 516980, 520125, 520258, 520918, 521923, 522492, 522931, 2643 and 2805).

Health \& Social Care Information Centre: http://www.ic.nhs.uk/. Hospital Episodes Statistics: http://www.hesonline.nhs.uk/Ease/ servlet/ContentServer?sitelD = 1937.

British National Formulary: http://www.bnf.org/bnf/index.htm. 